\title{
Diagnosing vulnerability and 'dangerousness': \\ Police use of Section 136 in England and Wales
}

\begin{abstract}
Police in England and Wales are empowered, under Section 136 of the Mental Health Act 1983 (s136), to detain individuals who are thought to be a danger to themselves or to others. Use of this authority is widespread, but varies substantially across districts and attracts controversy, both because of inconsistent application, and by the fact that it requires the police to make judgements about mental health. To study attitudes to and criteria for using s136 from the unique perspective of the police, we conducted focus groups with 30 officers in both urban and rural areas of three different regions across England and Wales. Group interviews were recorded, transcribed, and analysed using open and axial coding. The results indicate that use of this authority has major implications for police work and officers in all regions. Liaison with mental health services, whilst essential, is often perceived as ineffective due to resource constraints and the lack of availability of appropriate 'places of safety', especially in rural areas. The decision to invoke s136 is further complicated in individual cases by factors such as drug and alcohol use and 'contested conditions' such as personality disorders. Police decisions thus reflect an implicit values-based classification of and response to emotionally-disturbed behaviour, in light of available institutional and social supports. Tasked primarily with protecting the public and keeping the peace, police acknowledge their 'diagnosis' of risk often contrasts with that of mental health professionals.
\end{abstract}




\section{Introduction}

The potential for psychiatry to be perceived as an agent of social control has a long history associated with the development of the asylum, as well as playing a continuing role in involuntary treatment and the medicalisation of social deviance (Conrad, 2007). The process of medicalisation can be seen to depend on the relationship between professionals, and the extent to which definitions of the problem are contested (Malacrida, 2004). The introduction of specialised diagnostic systems [DSM, ICD] and the Mental Health Act [1953] in the mid twentieth century coincided with the civil rights and anti-psychiatry movements, amid debates about the origin of social problems and the social construction of diagnostic labels (Maden, 2007; Manning, 2006). Psychiatric practice has continued to be subject to social constructionist critiques ever since, but more recently from within psychiatry itself (Bracken \& Thomas, 2006).

In addition to the tensions between care and control, many psychiatric diagnostic categories are controversial and continue to be redefined in the two major classification systems: The International Classification of Diseases (ICD) published by the World Health Organisation, and the American Psychiatric Association's Diagnostic and Statistical Manual of Mental Disorders (DSM). The validity of these classification systems has been seriously challenged (Sartorius, 2010), in part by the growth of the valuesbased-medicine movement (Fulford, 2002).

\section{Section 136, dangerousness and vulnerability;}


Assessing perceived dangerousness and/ or vulnerability poses dilemmas to the agencies involved in invoking sections of the Mental Health Act which result in involuntary treatment, including s2, s3 and s135, and especially s136, the focus of this study. Sectioning generally requires shared decisionmaking between Approved Mental Health Professionals (AMPHs, usually social workers), psychiatrists, and police, who operate with different models and knowledge bases (Colombo et al 2003 ). Police in England and Wales are empowered under s136 to detain people in public places who are deemed to be a danger to themselves or others and remove them to a 'place of safety' (Docking et al 2008; Royal College of Psychiatrists, 2008). Use of this authority is widespread, but attracts controversy, as it requires the police to make initial judgements about the mental health status of the person involved. The procedure is intended to protect both disturbed individuals and the public, and rates vary substantially across regions (Borschmann et al 2010).

'Places of safety' have also been the focus of much of the s136 controversy, as lack of facilities and staffing mean that all too often these are police custody suites, adding to the trauma and stigma of the detention (RCP 2011). Since this study was conducted, the recommendation that $s 136$ suites be located in health facilities has been implemented in many regions, but there still appear to be problems in staffing these, especially outside normal working hours, when incidents are more likely to occur. Admission to $\mathbf{S 1 3 6}$ suites in hospitals are also allowed to exclude anyone who is obviously intoxicated, has committed an offence, or is violent and in need of restraint (Trendall and Gates 2011). 
At the time of this study, formal Police training in mental health varied a great deal regionally; at best limited (commonly a day or half day workshop), at worst non-existent (Lynch et al 2002). Since the Bradley Report (2009), £50 million has been spent on Mental Health and Liaison and the introduction of trained Police Mental Health Liaison officers to address this deficit, but police still have to make on the spot pragmatic decisions about perceived risk, which may or may not accord with professionals in the multi-disciplinary mental health teams. The immediate issue for police is the degree of emotional distress escalating into public disturbance, which may or may not translate into a diagnosable or treatable mental disorder. Two particularly difficult phenomena are the problem of dual diagnosis, where the individual is affected by alcohol or illegal drugs, and the complexity of diagnosing personality disorders.

\section{Personality disorders and dual diagnosis: diagnosis or guesswork?}

An estimated 40 per cent of people who have psychosis misuse 'substances' (alcohol, illict and prescribed drugs) at some time in their lives: more than twice the rate of people who have no experience of psychosis . People with a diagnosis of psychosis, such as schizophrenia or bipolar disorder, often report that they take drugs or drink alcohol to mask or help cope with symptoms, or counter some of the side effects of the medication, despite the risk that doing so may exacerbate their condition or render medication ineffective . Research evidence reveals that those with psychosis who misuse drugs and/or alcohol are more like likely to relapse and spend time on hospital wards, are less likely to take prescribed medication and more likely to 'drop out' of treatment and lose touch with mental health 
services. They are also more likely to take their own lives, get involved in illegal activities and become violent (UCL guidelines ). Dual diagnosis is also linked to personality disorder and social deviance (Kendall et al., 2009; Kirkman, 2008; Martens, 2008)

Originally termed psychopathy, what is now labelled antisocial or dissocial personality disorder is controversial because it is unclear whether an individual is 'mad or bad', the disorder lying as it does on the contested boundaries between mental illness and criminality. Although the term 'psychopath' retains socio-legal and cultural significance, clinically it has been discarded in favour of the less judgemental 'personality disorder' which includes a variety of other dysfunctional personality types.

Estimated at a combined prevalence of around $4.4 \%$ in the UK (Coid et al 2006), personality disorders are sometimes viewed as less 'legitimate' than other mental disorders, subsequently the propensity for self harm and suicidal behaviour, which is often symptomatic may largely go untreated (Kendall et al 2009).

In contrast, threatening behaviour or 'dangerousness' is of extreme public concern, often fuelled by the media (Corbett \& Westwood, 2005). The category of 'Dangerous and Severe Personality Disorder' (DSPD), referring to people who are capable of extremely violent or aggressive behaviour as a direct result of a personality disorder, was introduced in the UK after the much publicised case of Michael Stone. A contested category, DSPD includes aspects of antisocial and borderline personality disorder, and a similarity to the legal category of 'psychopathic disorder'. However, DSPD remains an administrative rather than a medical category, and does not appear in DSM or ICD. As such, it is viewed with scepticism by mental health practitioners who question whether they have a duty of care towards these individuals (Scott et 
al 2012). For police, the choice of whether to use s136 or a criminal arrest is a common one; a minor charge, such as breach of the peace, offers police an alternative option The London Development Centre Review found that in $20 \%$ of cases of s136 detention the individual had committed a criminal offence that was not charged (Bather, 2006) but this practice is controversial and has attracted detailed recommendations from the Royal College of Psychiatrists ( RCP 2008).

More generally, personality disorders and dual diagnoses may be disputed as genuine mental health conditions by mental health professionals despite the National Institute for Clinical Excellence (NICE) guidelines recommending an end to such diagnoses of exclusion :

'mental health professionals often do not recognise the main characteristics of these disorders: clinical presentation often results from co-morbidities such as depression or substance misuse; and people with a personality disorder may be considered responsible for their own condition, which is often viewed as untreatable' (Kendall, et al., 2009)

Inevitably, the continuing controversies around the contested status of both personality disorders and dual diagnosis reveal further how political and moral values shape risk assessment and decision-making in the implementation of s136 (Corbett \& Westwood, 2005).

\section{Previous research regarding $\mathbf{s} 136$}

Studies based mainly in London indicated that use of s136 is associated with social disadvantage, a diagnosis of schizophrenia, male gender, and Black British or Afro-Caribbean ethnicity (Docking et al. 2008; RCP 2008). Threatened or actual violence was the most common presenting problem 
leading to s136 detention, followed by threats or acts of deliberate self-harm (Simmons \& Hoar, 2001). A South London survey replicated the findings that Afro-Caribbean males were over-represented among s 136 detainees (Borschmann et al 2010). Studies carried out in rural England gave a rather different impression: in Gloucestershire, threatened or actual self-harm characterised the majority of cases, and the excess black detention rate reported in urban samples could not be confirmed (Laidlaw et al 2010). In Sussex, police used s136 to detain individuals in custody at particularly high rates (Docking, et al., 2008) and the study was inspired by discussions regarding possible explanations for the rates of s136 use in Brighton and Hove -- estimated to be as much as ten times the national average. While this disparity may reflect Brighton and Hove's generally high rates of drug and alcohol abuse, suicide, and mental health problems generally, this explanation does not fit with the fact that comparatively few detainees in this district are subsequently admitted to mental health units, either under compulsion or informally (Trendall and Gates 2011). Indeed, there appears to be an inverse relationship between $\mathrm{s} 136$ detentions in Police facilities and the availability of alternative 'places of safety' (Docking, et al., 2008; Royal College of Psychiatrists, 2008).

This is, however, a rapidly changing context, as recommendations by the RCP such as increasing the number of $\mathrm{s} 136$ place of safety suites within psychiatric in- patient facilities has been widely adopted since the fieldwork for this study was undertaken. Subsequently, the aim of this study was not to provide a 'state of the art' policy context of police use of s136, rather to 
provide largely unexplored and qualitative data concerning police officers' attitudes toward and experiences of implementing the powers of this controversial and continuously scrutinised section of the Mental Health Act.

\section{Method}

We used semi-structured focus groups to compare police attitudes and practices in six districts in England and Wales spanning urban, semi-rural and rural geographical locations. Through police mental health liaison contacts in Sussex, we identified six participating police stations; an urban and rural station was selected in each of three regions of the country:

1. South East England: Brighton and Hove and Burgess Hill

2. West of England: Exeter and Camborne

3. North Wales: Wrexham and Dolgellau

After clearance by the University of Sussex Research Ethics Committee (\#079727, 24 July 2006), permission to conduct focus groups was obtained from sergeants at each station. Four to six officers were recruited from each to participate voluntarily in $45-60$ minute semi-structured group interviews during 2006/7, facilitated jointly by the authors, a psychiatrist and a medical sociologist. Written informed consent was obtained in all cases, with the proviso that individuals would remain anonymous.

Interviews began with general questions about officers' understanding and experience of s136, and what criteria or circumstances were important in their decisions to apply it. Examples were invited where appropriate; officers were asked to avoid mentioning any details that could identify individuals. Detailed 
interview format and prompts are presented in the Appendix. Each interview was recorded and transcribed; resulting data were checked to ensure individual anonymity and analysed using open and axial coding (Bryman, 2004) and general thematic analysis (Braun \& Clarke, 2006) to identify both regional differences and common themes. Our findings are presented through three main themes; the first concerns the perceptions of police about their own expertise in decision making and ethical justification for using s136; the second explores complicating factors such as personality disorder and dual diagnosis in the need to respond pragmatically to risk. The final theme concerns the relationship between police and mental health services. Verbatim quotes and case study examples from focus group transcripts are used to illustrate the complex and often dramatic scenarios described.

\section{Results}

\subsection{Police knowledge and use of Section 136}

All officers interviewed had used s136, although rates varied greatly, the highest in rural Cornwall; one officer estimated an average of two per day with even higher rates during the tourist season:

\section{Camborne:}

[Those] that turn up to come into custody, l'd say on average two a day. As in they turn up as a 136 patient. Also, we have to arrest another 50 people, of those, four might also be assessed. From a community point of view we deal with it two or three times a week. Not 
me personally, but the team that I supervise. But, that would be at least triggered by the patrol officers, who actually go around dealing with things. You'd probably find each individual patrol officer dealing with one a week.

With the exception of Cornwall, the cities had higher rates than rural areas, the highest being Brighton and Hove. Rates in rural areas were thought to be exacerbated by the lack of mental health services and assessment suites. All officers interviewed considered s136 an important and useful law, appropriate for police use:

\section{Wrexham:}

As police officers, we are capable of dealing with people under 136, and we know when it needs to be used. I can't really see that anyone else can do it.

\section{Dolgellau:}

It is useful...we can take them out [of circulation]

\section{Brighton:}

Yes, we are the people that people call to these people, and we need something, otherwise we would be helpless to do anything. I definitely think we need it...

\section{Exeter:}

It's all very straightforward when they are obviously mentally impaired, because they are so...they are not making any sense...then it is straightforward and you know as a police officer that you are doing the 
right thing in taking them off the street, because they are a danger to themselves or to the public, yes, the power is very good. The power is very clean-cut. It's easy to bring them into custody, but then if someone is showing signs of mental illness, straight away we arrest them and bring them into custody, and it seems to break down after that.

Section 136 criteria are based on whether an individual is deemed to be a danger to themselves or others. In this study, the majority of police officers found this process reasonably uncomplicated, and completely justified in the interests of public safety:

\section{Brighton:}

(Question: Do you make a distinction for people with serious mental illnesses, such as schizophrenia?)

Yeah, obviously they are so different. You do have people with cuts on their arms...there are people who are clearly mentally ill, showing signs, and you can just see that they can't look after themselves. 136, we use that for both.

\section{Wrexham:}

You've just got to make a judgement call. Let someone else make the decision. We apply it correctly, nearly $100 \%$ of the time; you've got no option if this person is going to go off and harm themselves or someone else. If you've got nothing else, you bring them in. We use 136 as a tool to get them in and get them assessed.

Exeter: 
If they are concerned about the level of violence, they ask the police to turn up.We are there to make sure the people and the public are safe. Someone else has to make the decision if that person is mentally ill. We just go on if they are a danger to themselves, or aggressive towards other people, just on their behaviour. There is this one girl, she was moved around a lot, she was in a foster home. They couldn't handle her, so they called the police, because she trashed the place. We couldn't use 136 because she was in the house. So we used a [breach of the peace] to get her outside, and once she was outside we used 136. Sometimes we get called to a place of safety, to move them to another place of safety, but you can't use 136 within a house. We say whatever, "come look at the flowers", anything to get them outside the house, and as soon as we are out, right, there you go.

Camborne:

If they are incredibly violent 136 , and they should be with us, I would support that.

\subsection{Police training in mental health}

All interviewees had received minimal training about mental health in relation to s136. These ranged from a half day to 2 day workshops and focused mainly on the relevant aspects of the Mental Health Act (section 135 and section 136) with some training in psychiatric categorisations. Although most thought it had been useful, all officers 
interviewed said they would welcome more in-depth sessions, especially in regard to dealing with someone who is extremely agitated.

Wrexham:

(Question: Any aspects that would be particularly helpful?)

Training in how to listen and get people to talk

On the whole, experience was felt to be more important than training; advice from colleagues who had dealt effectively with past incidents was particularly valued. Although training was seen as useful, they did not identify themselves as mental health professionals and could not be expected to make a diagnosis. Rather, it was important to develop confidence in dealing with apparent mental illness

\section{Brighton:}

...a lot of it is down to circumstance... main thing is to treat them right because they are not criminals. For example if someone is jumping off a bridge...that is usually an easy one. It is something that seems like they are a danger to themselves or other people, doesn't seem totally there. With no trousers on, no top on, no clothes on at all.

Some officers would have liked to have more training regarding the diagnosis of personality disorders. Not surprisingly, they had difficulty understanding that these could be classified as mental illnesses, but at the same time seen as untreatable by mental health professionals. 


\section{Dolgellau:}

For personality disorders...something like that would be perfect to have an hour's lesson on ... so that we learn what we are looking for...to give you the basics... like the basics in first aid...the basics in mental health...

\section{Brighton:}

Particular personality disorders are untreatable, and I think a number of our 136 s that we detain turn out to be diagnosed by the doctor as having a personality disorder. One could argue that if we were able to make that distinction in the first place, that detention might not have taken place. Would that stop us actually using 136 on the ground? Should it stop us from using 136 ? That's where I come back to, a lot of information can actually be dangerous. Because you are then asking the officers to make an assessment, which they are not trained to do. And if somebody misunderstood training about personality disorder and then didn't detain them, and then they walk around the corner and assault somebody, and it was found out that he had made that decision, where is the background coming from that is giving us that decision to make. I think there could be an argument on the impact on the individual who has been detained, who has a personality disorder, does that affect them negatively? Where are we with mental health treatment in this country?

\subsection{Complicating factors: substance misuse and dual diagnosis}


Substance use, in the form of illegal drugs and alcohol, affects police decisions regarding s136 as it bears on the issue of whether antisocial behaviour indicates a mental disorder. In Wrexham, for instance, officers estimated that nine out of ten potential s136 incidents involved substance use usually alcohol. In these cases they do not proceed with s136 if they think it will be pointless:

.. we know straight away that the hospital won't accept them.

So we bring them here first, get assessed here, sober up here, then they go home..

As indicated earlier (Kendall, et al., 2009), there is a high incidence of substance use co-morbidities in personality disorders and psychotic conditions, especially bipolar disorder. Police officers were keenly aware of this:

\section{Brighton:}

If I have a concern about an individual's mental health, we would be on the phone to various partner agencies, going "Do you know so and so? Am I right to feel there is a mental health concern here?" And they would tell us yes/no there is a history/no history. There is a potential that the mental health team is watching and wanting to make a proper assessment. The difficulties we have is the dual diagnosis. Where somebody who "needs help" isn't given that help, from our perspective, because of the risk of drugs and alcohol deflecting that diagnosis. 
Some officers appeared confident that they were able to make accurate distinctions:

\begin{abstract}
Exeter
Just drink and drug induced vs. mental health? It's quite clear to us. It's just dealing with people, get to know the signs. Every day we deal with drink and drug people, so it's... we can tell the difference. Obviously there are times when it is combined...
\end{abstract}

\author{
Burgess Hill \\ I just think it's something that grows with you. And the more you deal \\ with it the more you see of it. At the beginning I had trouble \\ determining whether someone was a 136 or was high on drugs...there \\ are slight similarities there in that they are slightly weird. But as you \\ work, you tend to pick up on what's what.
}

Nearly all the officers we interviewed understood the complexities involved in the scenario of dual diagnosis, but many felt confident that they could distinguish between people who were intoxicated and those with mental health issues. Although they readily acknowledged they were unable to diagnose and indeed had no aspirations to do so, they relied on instinct and experience to make these distinctions. 


\subsection{Dangerousness and perceived threat}

Each force had examples of extreme cases where there was an urgent duty to protect the public, irrespective of whether the person in question had a real mental illness, as in the following examples:

\section{Brighton:}

...in ${ }^{* * * * *}$ we've just had two very bizarre events where the person has walked down the seafront, to the children's play area, with a battleaxe, and knife, and [other] collection of weapons. He was scary. There was another walking down the street waving a scimitar. They had [committed] criminal offences by doing what they did, but also you've got to start saying "they are not quite right" -- there is a potential medical need here. So both of those were detained on criminal acts, as well as a 136 detention.

\section{Exeter:}

We always deal with the most extensive offence. If there is a criminal charge, they will be arrested under that. The doctors will assess them first, and determine if they are fit. Sometimes they are sectioned after they have been taken in. If there is a substantial offence we will deal with that but they will be assessed. If they are not fit to be dealt with, they will be sectioned.

In these cases, where there were clear indications of potential public danger, the response was always to arrest rather than use s136, even if officers knew the individual was a mental health service-user. Thus the vast majority of 
s136 use was in cases where individuals were in danger of harming themselves.

\subsection{Vulnerability, self harm and suicidal behaviour}

As indicated above, the interview transcripts reveal the extent to which the pragmatics of safety in the public interest are applied to the majority of cases involving extreme cases of self harm and suicidal behaviour. Moreover the case studies indicate a high degree of compassion for desperate individuals whose psychiatric status is often contested by the health professionals as in the following account :

Camborne:

We held one woman in the cell for 27 hours because...she was being physically restrained because she had been released from the hospital, went straight into the garage, took an overdose, the police officers had detained her under 136, took her back to hospital, the hospital turned around and said, "oh, we just released her. She isn't a mental health patient. We don't want her. We're not letting her back in." Well the police [are] not in the position to make that decision, so she came back to the custody centre, and she had to be restrained for 27 hours by two people because she had cut marks up her arms, requiring stitches...had bashed her head in continuously, tried to choke herself. She ripped some stitches out, got taken to the hospital, assessed, and they said "no, no, we don't want her" and they released her. Then we couldn't get her home, so the police officers that were with her, two female officers from here, had to go with...to her home, which is about 
an hour away, and I had to follow up from here. So we have three officers dealing with her. And this is a lady with a broken back, with pins in it, a chest cavity with pins in it. On crutches because she had jumped off the fire duct trying to commit suicide and it didn't work and she lived. And they say she hasn't got mental health issues. She has a "borderline personality disorder"...and you call the doctor and the doctor phones you back and says, "if she is presenting to you the same as she did to us yesterday, just release her." And what if she dies within 1 hour or 24 hours?

Another scenario involved rescuing a confused and disorientated elderly woman, presumably suffering from dementia, was described in a similarly compassionate manner:

\section{Exeter :}

You just brought them in using 136 because they were wandering around outside, not breaking any laws. So you bring them in for their own safety. Or they broke a law, so you bring them in, and they are safe, not wandering around any more. I had a very old lady who had wandered the streets, we sectioned her in a grammar school. She was just in a world of her own. We drove her around to see if she recognized anything, and she saw her old house, where she had lived 25 years ago. We brought her here as a place of safety under 136 . We found the council [nursing home] where she was living, where she had wandered out from that morning. 
The use of s136 in cases of perceived suicidal behaviour and self-harm was a recurrent theme in each region, and officers were candid about their use of the Act to protect a wide range of vulnerable people. These individuals may not have been 'ill' by medical criteria, but were nevertheless desperately in need of help:

\section{Wrexham:}

Sometimes 136 is used for a back-cover....Sometimes it is a selfharmer, and you are trying to get them to a place of safety or trying to get someone else to take responsibility for them, but we know that $80 \%$ of the time they will be fine if you leave them wherever. It is that $20 \%$, where, if you as a police officer haven't made the decision to take them and get them assessed, it will come back on you if they do actually do something to themselves. So I would say we use 136 in that situation.

Rather than using complex psychiatric criteria, officers seemed to rely on 'common sense' to make judgements about the danger an individual might pose to themselves or others:

\section{Burgess Hill:}

I think it's used when perhaps nothing else will work....like when someone wants to commit suicide. Sometimes we may use [s136] inappropriately, but if we don't use it and they are going to do something... obviously some people aren't mentally ill but are just 
going through a stressful period, and they don't need to be taken into custody, but what do you do?

When we use 136, its not always actually people who have mental illnesses, it's the people who are stressed. Who are down on hard times, and are trying to commit suicide. Especially youngsters, or old people, you know, marriage break-ups, and so you use 136, but they are the people who need counselling, not mental health [services]. So we are not always using 136 for mental health, its more for people who can't look after themselves.

Police officers felt morally justified working in this manner, both in the interests of protecting the public, and as a means of helping vulnerable individuals. Although at risk of criticism for inappropriate usage of $s 136$, police officers were confident that it was protective rather than coercive. The consensus was that there was no stereotypical 'case' in terms of gender, ethnicity, sexuality, age or any other social characteristics, with the exception of Dolgellau, where it was thought that s136 was more likely to used with women than men.

\section{Collaboration with mental health services}

All teams discussed working proactively with mental health services; in three of the areas, officers described their collaboration in very positive terms:

\section{Brighton:}

We have a very proactive relationship with mental health patients. We do have a relationship with our mental health team, and we work 
together to deal with an individual that poses a risk or concern....just recently we've been involved in more joint detentions of 136, where we've worked alongside...if they say "yes, we need them detained" for further assessment, we'll actually go detain under 136, and go through that process..

\section{Wrexham:}

My experience with 136, many time, [is that] the police come, and then within five minutes, a social worker is there. ..

Rural teams were generally more negative, one indicating that they might avoid using $s 136$ because negotiations with mental health services were timeconsuming and rarely helpful:

\section{Dolgellau}

For someone who is suicidal, it is not my first port of call. If it was a system where you could easily take the person and properly get them help, we would probably use it a lot more.

(Question: Does that stop you from using it?) well, if it is 2 am at the station and they have to call the social worker who is going to turn up in 2 hours, and then another 2 hours, and then they say we don't really want to section them...it's not my place. I am not trained to look after these people, I'm not a hospital.

Physical distance from mental health services, and consequent drain on 
police time, were particular issues for geographically isolated teams in South West England and North Wales. There was nonetheless consensus across teams regarding the overall lack of resources and support from other services, with each area having its own 'horror' stories:

\section{Brighton:}

There was an incident where, it wasn't me, it was a member of my team who said that their colleague actually spent a significant amount of time talking to them and got them sectioned and detained under 136 in hospital. That person washed up three days later under a bridge -the CCTV showed they were alone, just jumped off the edge. That was one experience where I felt incredibly frustrated that it was just wrong, that person was not in the right frame of mind...something was missing, he needed help with, and the system seemed to fail him. I remember feeling immensely frustrated in that situation. There are situations with domestic violence where we KNOW that somebody is going to kill somebody at some point, but our hands are tied by what we can prove, and what we can't prove.

\section{Wrexham:}

The last one was at the hospital. We took her to a secure unit, and they refused to accept her. She knew members of staff. She had been picked up in the street, and we were asked to help at the hospital. And they said we've got to have specifics. She was just walking around naked...mental health issues, and we were asked to help them out. 
The doctors in casualty said, "Well, there is nothing we can do with her in casualty, and I think she is OK". So we had a bit of a heated discussion...so they were happy just to let her go, with no clothes on... So if you are happy to release her, to sign and say you are happy to release her into the general public, then fine. So he decided to say she went to a secure unit, and they refused, so we had to take her back into custody. So I was not very impressed.

\section{Dolgellau:}

A few months ago, there was a woman who had taken a bottle of paracetamol, she wanted to die. She was refusing treatment at the hospital, and you can't just leave her, and you can't make her accept treatment, so we take her to [the nearest psychiatric unit] and we get there and they say "we can't sort her out until she's been to casualty", So we go there, and "sorry, it's a mental health issue, she doesn't want treatment, so bring her back to the PU". You go back and forth a dozen times, and you think "who is going to help this girl?"...not the professionals and we can't take her into custody because we haven't got the training...

In many cases where follow up support was denied, police eventually ended up caring for $\$ 136$ detainees, far exceeding their normal duties:

\section{Exeter:}

I've been asked to help restrain someone when they...to calm them 
down. You know, we don't have to do that. We try to assist, but we really shouldn't do that. If its not something we have to do....the hospital....wait for them to calm down, then if not you restrain them and give them some kind of medication. We normally do what we're asked, don't we?

(agreement from other officers)

\section{Camborne:}

My last day with night shifts we had a guy who, a 136 who...covered himself from head to toe in excrement, covered his cell, and managed to rip out the toilet from the floor.We don't have special training to deal with these people. We just check on them every half an hour.

In all regions, police described being constrained in using $\$ 136$ by a lack of detention facilities. Moreover, local psychiatric hospitals often lack the secure units needed to effectively manage these crises, leaving police officers to choose whether or not to detain vulnerable and/or potentially dangerous individuals:

\section{Brighton}

There are people who are in need of medical help who pose a significant risk to anyone around them [including mental health workers ]... we need the appropriate ways to contain that person, not only for their own personal safety but also the safety of others. And any such establishment should be geared up for that work. We have a mental 
health hospital 10 minutes from here, and we are not allowed to take our concerns to that location under 136

\section{Camborne:}

We got to the point two weeks ago where we had the custody centre closed because we got three mental health patients in one day. And we couldn't put any of them in cells. That happened on a Tuesday, and the Sunday we closed because we had five 136 patients in at the same time... we can't staff it. They are such high risk intake and they take so much staff, and then we've got colleagues travelling to prisons or hospitals an hour away.

The lack of resources, especially secure psychiatric facilities, means that police all too often take on the role of mental health carers, despite their lack of training and frequent competing demands for their time.

\section{Discussion}

The use of Section 136 has been under increased scrutiny over the last five years, as the rate of detentions in England rose significantly, from an estimated 7035 between 2007-8 to 8495( 2008-9) and 12038 (2009-10), (Royal College of Psychiatrists 2011). Theories abound to explain this increase, including that police use $\mathbf{s} 136$ because it is easier and less timeconsuming than arrest (Borschmann et al 2010 ) but our study did not support this view, and there appears to be a scarcity of research which addresses the police perspective. 
In our study, the police officers we interviewed appeared familiar and reasonably confident with $\mathrm{s} 136$ procedures, although none were formally assessed. The decision to apply s136, regardless of the availability of a 'place of safety', was open to interpretation and dependent on case-by-case judgement, with the welfare of the vulnerable person being the most important criteria. Acknowledging both their lack of knowledge and the ethical difficulty of making judgements about mental disorder, police were nonetheless ambivalent about the value of specific training to address these problems. Aware of their inability to make 'expert' diagnoses, they felt experienced enough to tell intuitively when something was wrong with someone's mental state. In these instances, the criteria of serious risk of harm to self or others, ergo vulnerability or dangerousness, were paramount; s136 would be applied whether or not it would lead to a hospital admission, proving useful in containing potentially life-threatening situations.

Our results show that the decision to invoke s136 depended on institutional and structural factors, as well as on social context and other particulars of individual cases. Police decisions, whether made urgently in a crisis or following thoughtful assessment, were found to reflect an implicit, processbased classification of mental disturbance and what needed to be done about it. Despite having little or no formal training in psychiatry, officers were aware that mental illness, or severe emotional distress, deserved to be recognized and treated compassionately, hence their reluctance to use criminal law to charge mentally ill offenders. In almost all cases, officers expressed the view 
that s136, or other sections of the Mental Health Act, was a more appropriate intervention.

Personality disorder, as discussed earlier, is a distinctive, highly contested psychiatric diagnosis which commonly presents as public disturbance, often attracting police attention and s136 detention (Spence \& McPhillips, 1995) and which may be further complicated by drug or alcohol misuse. Repeat presentations by vulnerable individuals, as in some of the examples described here, are common. This may be partly due to the fact that mental health personnel often view borderline or antisocial personality disorders as 'untreatable'. Furthermore, s136 suites will generally not accept people who are intoxicated. This leaves the police in a difficult and often unsupported position, as shown in our results. In some cases, custody suites were literally being used to prevent further suicide attempts by compassionate officers who were reluctant to abandon a person who appeared to need support and protection. There is a movement towards abandoning the term "personality disorder' altogether and replacing it with the term 'adaptation disorder', which can be graded into mild, moderate and severe, maintaining some continuity with current classification. This may reduce the stigmatizing component of the diagnosis and emphasise positive efforts to improve adaptation (Svrakic, et al., 2009)

Deficits in inter-agency communication and collaboration have been previously reviewed (Borschmann et al 2010). The Independent Police Complaints Commission (Docking, et al 2008) and the Royal College of 
Psychiatrists ( 2008, 2011) have each offered useful recommendations to address these shortcomings and promote effective collaboration. Our findings show that the relationship between police officers and mental health services can, at least in principle, be optimistically described as complementary. While police officers clearly appreciated the need for Places of Safety to be located in mental health facilities and offer prompt and appropriate expertise, the response to many incidents, especially after hours, was that the mental health services were disorganised, poorly resourced or frankly unavailable.

Moreover, exclusion criteria such as alcohol and drug consumption or perceived risk of violence precluded admission to the 136 suites in many cases. All too often, police custody suites were the only resource, and while the amount of $s 136$ suites have increased since the time of this study, there still appear to be issues around the adequate staffing of them (Trendall and Gates 2011).

In conclusion, police perceptions of mental illness appear to be pragmatic and heavily influenced by the availability of institutional and social supports; they inevitably see themselves as the last resort in caring for 'the people that nobody else wants to deal with, not even the 'so-called caring professions', as one officer put it. Thus, in this study, the police can be seen to be encompassing a form of value-based practice which acknowledges the loss of medical hegemony over diagnosis and decision-making in multidisciplinary mental health teams (Colombo et al 2003). Subsequently, their unfailing, and often compassionate, response to the public expression of extreme emotional distress was all too often in conflict with that of the mental healthcare 
services, which were perceived to be more focused on defining and treating mental illness than managing the associated social disturbance. The overwhelming incidence of police sectioning powers being used in cases of people threatening suicide or engaging in self harm suggests that police interpret the criteria to enforce s136 Mental Health Act very literally, as a suicide prevention strategy.

Endnote: We would like to thank Dr Jason Read, Judith Matthews and Jill Walker for making this pilot study possible, and Jill Masters for assisting with transcript analysis. One of the authors, GB, has been awarded British Academy Senior Research Fellowship to conduct further research in Sussex and is working in collaboration with Sussex Police and Sussex Partnership Foundation Trust ( REC ref 12 LO 2031). 


\section{References}

Bather, P. (2006). Review of Section 136 Mental Health Act. London: London Development Centre.

Borschmann, R. D., Gillard, S., Turner, K., Chambers, M., \& O'Brien, A. (2010). Section 136 of the Mental Health Act: a new literature review. Medicine, Science \& the Law, 50(1), 34-39.

Bracken, P., \& Thomas, P. (2006). Postpsychiatry: mental health in a postmodern world. Oxford: Oxford University Press.

The Bradley Report (2009) Lord Bradley's review of mental health problems and learning disabilities in the criminal justice system www.dh.gov.uk/publictations

Braun, V., \& Clarke, V. (2006). Using thematic analysis in psychology. Qualitative Research in Psychology, 3(2), 77-101.

Bryman, A. (2004). Social Research Methods (2nd ed.). New York: Oxford University Press.

Coid, J., Yang, M., Tyrer, P., Roberts, A., \& Ullrich, S. (2006). Prevalence and correlates of personality disorder in Great Britain. Br J Psychiatry, 188, 423431.

Colombo, A., Bendelow, G., Fulford, B., \& Williams, S. (2003). Evaluating the influence of implicit models of mental disorder on processes of shared decision making within community-based multi-disciplinary teams. Soc Sci Med, 56(7), 1557-1570.

Conrad, P. (2007). The Medicalization of Society: On the Transformation of Human Conditions into Treatable Disorders. Baltimore: John Hopkins University Press.

Corbett, K., \& Westwood, T. (2005). Dangerous and severe personality disorder: a psychiatric manifestation of risk society. Critical Public Health, 15, 121-133.

Docking, M., Grace, K., \& Bucke, T. (2008). Police Custody as a "Place of Safety": Examining the Use of Section 136 of the Mental Health Act 1983. London: IPCC.

Fulford, K. W. (2002). Values in psychiatric diagnosis: executive summary of a report to the chair of the ICD-12/DSM-VI Coordination Task Force (Dateline 2010). Psychopathology, 35(2-3), 132-138.

Greenberg, N., \& Haines, N. (2003). The use of Section 136 of the Mental Health Act 1983 in a family of rural English police forces. Medicine, Science \& the Law, 43(1), 75-79. 
Kendall, T., Pilling, S., Tyrer, P., Duggan, C., Burbeck, R., Meader, N., et al. (2009). Borderline and antisocial personality disorders: summary of NICE guidance. BMJ, 338, b93.

Kinton, M. (2008). View point. Call for closer monitoring of Section 136. Mental Health Today, 37.

Kirkman, C. A. (2008). Psychopathy: a confusing clinical construct. J Forensic Nurs, 4(1), 29-39.

Laidlaw, J., Pugh, D., Riley, G., \& Hovey, N. (2010). The use of Section 136 (Mental Health Act 1983) in Gloucestershire. Medicine, Science \& the Law, 50(1), 29-33.

Lynch, R. M., Simpson, M., Higson, M., \& Grout, P. (2002). Section 136, The Mental Health Act 1983; levels of knowledge among accident and emergency doctors, senior nurses, and police constables. Emergency Medicine Journal, 19(4), 295-300.

Maden, A. (2007). Dangerous and severe personality disorder: antecedents and origins. Br J Psychiatry Suppl, 49, s8-s11.

Malacrida, C. (2004). Medicalization, ambivalence and social control: mothers' descriptions of educators and ADD/ADHD. Health (London), 8(1), 61-80.

Manning, N. (2006). DSM-IV and dangerous and severe personality disorder-an essay. Soc Sci Med, 63(7), 1960-1971.

Martens, W. H. (2008). The problem with Robert Hare's psychopathy checklist: incorrect conclusions, high risk of misuse, and lack of reliability. Med Law, 27(2), 449-462.

Morgan, D. (2004). Mad or Bad? A critique of proposals for managing dangerously disordered people. Journal of Community \& Applied Social Psychology, 14, 104-114.

Royal College of Psychiatrists. (2008). Standards on the use of Section 136 of the Mental Health Act 1983 London: RCPsych.

Royal College of Psychiatrists. (2011). Standards on the use of Section 136 of the Mental Health Act 1983 London: RCPsych

Rutherford M. (2010) Blurring the boundaries:the convergence of mental health, the criminal justice system, legislation, policy and practice Sainsbury Centre for Mental health

Sartorius, N. (2010). Revision of the classification of mental disorders in ICD11 and DSM-V: work in progress. Advances in Psychiatric Treatment, 16, 2-9.

Scott, S., Jones, D., Cane, R., Bendelow, G., \& Fulford, B. (in press, 2010). 
The lide to pragmatism: a values based understanding of 'dangerous' personality disorders. Health Sociology Review.

Simmons, P., \& Hoar, A. (2001). Section 136 use in the London borough of Haringey. Medicine, Science \& the Law, 41(4), 342-348.

Skodol, A. E., \& Bender, D. S. (2009). The future of personality disorders in DSM-V? Am J Psychiatry, 166(4), 388-391.

Spence, S. A., \& McPhillips, M. A. (1995). Personality disorder and police section 136 in Westminster: a retrospective analysis of 65 assessments over six months. Medicine,Science \& the Law, 35(1), 48-52.

Svrakic, D. M., Lecic-Tosevski, D., \& Divac-Jovanovic, M. (2009). DSM axis II: personality disorders or adaptation disorders? Curr Opin Psychiatry, 22(1), 111-117.

Trendall M. Gates S. (2011) Assessment of persons under sections 135 and 136 of the Mental Health Act. Pan Sussex Mental Health Act Monitoring Group, Sussex Partnership NHS Foundation Trust

Wolff, N. (2002). Risk, response, and mental health policy: learning from the experience of the United Kingdom. J Health Policy Law, 27(5), 801-832. 


\section{Appendix. Semi-structured interview format and prompts}

Over the last year, how many times have you been involved in an incident in which Section 136 was considered?

(if more than 10, how many in last 3 months?)

(if still more than 10, how many in last 1 month?)

Roughly how many of these incidents resulted in s136 being applied?

Is $s 136$ always the best intervention? If not, why not?

Where is your designated 'Place of Safety'? Is there more than one? Is it (are they) appropriate?

Can you describe the most memorable incident you have been involved in, during which s136 was considered?

prompt: what made it memorable?

prompt: was this the best intervention?

If not, what should have happened?

prompt: was this your most recent experience ?

What was the extent of your involvement in this case?

At what point did your involvement end?

prompt: did you have any contact after removal to the Place of Safety?

In your experience are some people more likely to be sectioned under 136

than others? Who and why?

prompts for: gender / age / ethnicity / sexuality 
Although there are legal criteria for s136, what are your main criteria for using the section in practice?

How do you see your role in these situations?

prompt: is it a role you are comfortable with? Why or why not?

When and how did you learn about using s136?

Was the training adequate? Why or why not?

To what extent did the training involve mental health services? 